\section{Desvendando Enigmas Históricos: Relato de Prática de Uma Prova Game}

\section{Resumo}

Atividades desafiadoras e lúdicas mobilizam os alunos favorecendo, assim, o processo de aprendizagem. Com este Artigo, pretendemos compartilhar nossa experiência com uma "prova game", cujo objetivo foi avaliar o aprendizado dos alunos por meio de habilidades requeridas em uma prova trimestral em formato de um jogo, ressignificando a ideia de avaliação com exercícios tradicionais por enigmas a serem desvendados.

Palavras-chave: Avaliação. Ensino de História. Jogo. Ludicidade. Relato de prática.

\section{Abstract}

Challenging and playful activities mobilize students, thus favoring learning process. In this article, we intend to share our experience with a "game test", whose objective was to evaluate students' learning through the skills required in a quarterly game format, re-signifying the idea of assessment with traditional exercises, by means of puzzles to be unraveled.

Keywords: Assessment. History teaching. Game. Playfulness. Practice report.

\section{Introdução}

"O aprendizado necessita de motivação para um envolvimento intenso, o que é atingido pelos games." MATTAR, 2010, p. XIII.

Sabemos que atividades desafiadoras e lúdicas mobilizam os alunos e fazem com que o interesse deles pela aula aumente, favorecendo, assim, o processo de aprendizagem.

Pesquisadores como Brougère (2002), Costa (2017) Leffa e Pinto (2014), Mattar (2010) e Kishimoto (2000), dentre outros, apontam que os jogos podem promover diversas habilidades, como tomada de decisões, raciocínio estratégico, concentração e resolução de problemas.
Prof. ${ }^{a}$ Me. Fernanda Filgueiras.

Mestre pela USP -

Universidade de São Paulo/

Programa Interunidades

da América Latina (2014);

licenciada em História pela

Universidade Cruzeiro

do Sul (2009) e bacharel

em História pela mesma

Instituição (2011). Nove anos

de experiência em docência na Educação Básica.

Atualmente, docente na

Escola Canadense Maple

Bear Klabin e na Rede

Municipal de Ensino de São

Paulo/SP. Autora do livro

Em defesa de Nuestra

América Antropofágica. 
Assim:

A atenção pode se manifestar na curiosidade e interesse que o jogo desperta, trazendo ao mesmo tempo surpresas e incertezas: as ações de um jogo partem de sementes aleatórias que introduzem uma variação constante, de modo que o usuário não sabe de onde pode surgir o adversário, por exemplo, ou que estratégias ele poderá usar. A relevância, por sua vez, pode estar na missão a ser cumprida e nos métodos que devem ser usados para executá-la; (...) A confiança está relacionada à expectativa de sucesso: por mais difícil que seja a etapa de um jogo, o usuário sabe que em algum momento encontrará uma solução e passará para a etapa seguinte. A satisfação, finalmente, está em vencer cada etapa, conseguir o reconhecimento pela habilidade demonstrada, possivelmente com a obtenção de medalhas e troféus. $\bigcirc$ jogo, na sua essência, é uma atividade fundamentalmente motivadora (LEFFA; PINTO, 2014, p. 361)

Um dos maiores desafios enfrentados pelos professores é, justamente, despertar o interesse do aluno que pode oscilar e, em efeito cascata, causar desinteresse que corrobora com o aumento da indisciplina, comprometendo todo o trabalho docente. Para tanto, é importante que a Escola, como espaço de produção e socializacão de ideias e saberes, esteja aberta para as expectativas trazidas pelos alunos do século 21.

De acordo com Paulo Freire (1996), "Ensinar exige comprometimento", uma vez que "Não posso ser professor sem me pôr diante dos alunos, sem revelar com facilidade ou relutância minha maneira de ser, de pensar politicamente. Não posso escapar à apreciação dos alunos" (FREIRE, 1996, p. 59).

Essa discussão nos leva a refletir sobre o quão importante é manter acesa a chama do processo de troca e interação entre alunos e professores e intensificar esse gosto pelo ensino prazeroso e lúdico na formação continuada de nós, professores, e a preocupação em entender que há a necessidade de nos reinventarmos e revermos nossa prática em sala de aula, como nos lembra Paulo Freire: "Por isso é que, na formação permanente dos professores, o momento fundamental é o da reflexão crítica sobre a prática. É pensando criticamente a prática de hoje ou de ontem que se pode melhorar a próxima prática (FREIRE, 1996, p. 22)

A Escola, portanto, precisa oferecer desafios aos seus alunos a cada etapa da trajetória escolar, para que o aluno assuma os objetivos que ele consiga alcançar, transformando cada desafio em conquista:

O princípio da superação leva-nos do mundo que temos para o mundo que queremos, que é um dos postulados básicos da educação. O que temos no mundo dos games é exatamente o que queremos para a educação: alunos totalmente concentrados em suas atividades, esforçando-se ao máximo para superar seus limites (LEFFA; PINTO, 2014, p. 370).

Cabe salientar que o jogo, por si só, não deve ser entendido como uma substituição das práticas didáticas próprias do processo educativo e, sim, uma possibilidade de contribuição com esse processo, por meio da ação planejada pelo professor, visando a uma finalidade pedagógica. Dessa forma, "O jogo não pode ser visto, apenas, como divertimento ou brincadeira para desgastar energia, pois ele favorece o desenvolvimento físico, cognitivo, afetivo, social e moral" (KISHIMOTO, 2000, p. 106).

Portanto, o jogo não é um fim em si mesmo, mas um meio para contribuir com o desenvolvimento da aprendizagem dos alunos. Sendo assim, o professor tem o desafio de tornar as atividades escolares mais interessantes, a fim de despertar no aluno do século 21 o prazer em aprender.

Dessa maneira: "O jogo bom é aquele que vicia, despertando no jogador o desejo de continuar jogando, às vezes, a ponto de querer que o jogo não termine. O mesmo vale para a sala de aula: a aprendizagem boa é aquela que vicia, 
despertando no aluno o desejo de continuar estudando" (LEFFA; PINTO, 2014, p. 372).

Considerando que o jogo, em suas multimodalidades, faz parte da experiência cotidiana dos alunos, resolvemos, então, aliá-lo, como instrumental didático-pedagógico, ao processo de aprendizagem das aulas de História.

\section{Relato de Prática}

O desafio de trabalhar os conceitos históricos, por vezes abstratos, com alunos de $6^{\circ}$ ano do Ensino Fundamental II, levou-nos a encaminhar nossa prática a uma abordagem mais lúdica. Nessa perspectiva, todo o planejamento curricular do $6^{\circ}$ ano vem sendo pensado, por nós, por meio de dinâmicas que visam a despertar o interesse educativo dos alunos.

Dados os limites acadêmicos inerentes a este Artigo, dentre outras práticas lúdicas desenvolvidas em nosso dia a dia escolar, escolhemos compartilhar nossa primeira experiência com uma "prova game".

Nosso objetivo foi avaliar o aprendizado dos alunos por meio de habilidades requeridas em uma prova trimestral em formato de um jogo.

Uma proposta de ressignificar a ideia de avaliação com exercícios tradicionais, por enigmas a serem desvendados, como mostra a orientação inicial de nossa prova game, representada na Figura 1, a seguir:

Está preparado? Então, vamos nessa!

Figura 1 - Orientação inicial da Prova Game

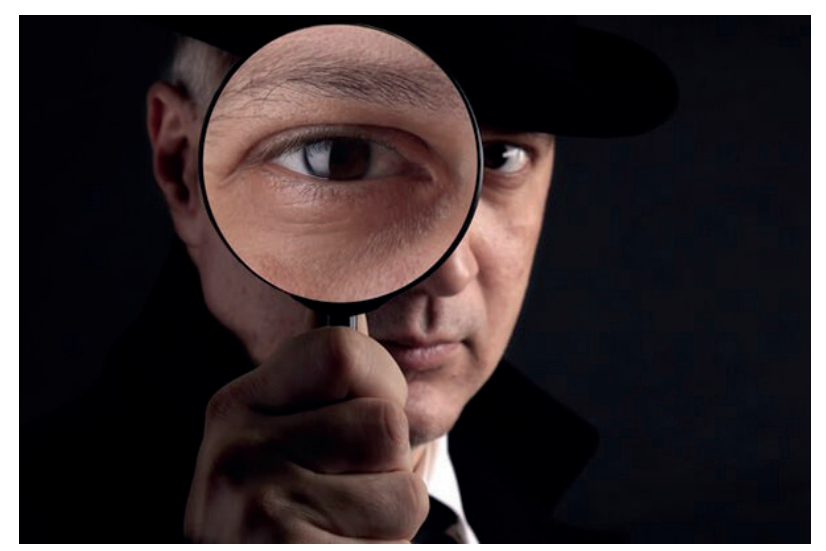

Fonte: elaborada pela autora.

Nas aulas de História, os alunos da professora Fernanda são seus detetives. Ela sempre dá novas missões para eles cumprirem. Agora, você terá a missão de desvendar um mistério histórico! Siga as pistas para desvendar os enigmas. A cada enigma desvendado, você acumulará pontos. Sua missão é conseguir, pelo menos, 70 pontos!

A prova contou com oito enigmas (questões) de pontuação variada, totalizando 100 pontos, demonstrados no Quadro 2, e foi respondida por 30 alunos dos $6^{\circ}$ anos A (19 alunos) e B (11 alunos) da Escola Maple Bear Klabin.

No Quadro 1, temos os conteúdos trabalhados ao longo do $1^{\circ}$ trimestre (fevereiro a abril/2019) correlacionados aos respectivos enigmas, conforme apontado no Quadro 1.

Quadro 1 - Conteúdo Trimestral

\section{Conteúdos $1^{\circ}$ trimestre $2019-6^{\circ}$ anos A e B}

\begin{tabular}{|l|c|}
\hline Por que estudamos História? & Enigma 1 \\
\hline $\begin{array}{l}\text { Como trabalha o } \\
\text { historiador? }\end{array}$ & Enigmas 1, 2 e 4 \\
\hline $\begin{array}{l}\text { A História em } \\
\text { nosso cotidiano }\end{array}$ & Enigma 5 \\
\hline $\begin{array}{l}\text { A origem dos } \\
\text { seres humanos }\end{array}$ & Enigma 3 \\
\hline $\begin{array}{l}\text { Das aldeias } \\
\text { às cidades }\end{array}$ & Enigma 3 \\
\hline $\begin{array}{l}\text { O povoamento } \\
\text { da América }\end{array}$ & Enigma 4 \\
\hline $\begin{array}{l}\text { A sociedade } \\
\text { da Mesopotâmia }\end{array}$ & Enigmas 5 e 6 \\
\hline A sociedade egipcia & Enigmas 7 e 8 \\
\hline
\end{tabular}

Fonte: elaborado pela autora.

Por sua vez, elaboramos cada enigma com o objetivo de avaliar o aprendizado adquirido pelos alunos, não apenas no sentido de reprodução dos conteúdos simplesmente, mas sim, a capacidade de os alunos demonstrarem determinadas habilidades na aquisição desses mesmos conteúdos atendendo às expectativas explicitadas no Quadro 2, a seguir. 
Quadro 2 - Descrição da prova

\begin{tabular}{|c|c|c|c|}
\hline \multicolumn{4}{|c|}{ RESULTADOS OBTIDOS } \\
\hline Enigmas/Questões - expectativas & $\begin{array}{l}\text { Atingiram a } \\
\text { expectativa }\end{array}$ & $\begin{array}{c}\text { Atingiram } \\
\text { parcialmente a } \\
\text { expectativa }\end{array}$ & $\begin{array}{l}\text { Não atingiram } \\
\text { a expectativa }\end{array}$ \\
\hline 1 - Classificar fontes históricas - 7,5 pontos & 28 alunos & 1 aluno & 1 aluno \\
\hline 2 - Definir conceitos históricos - 12,5 pontos & 25 alunos & 5 alunos & 1 aluno \\
\hline 3 - Organizar informações - 20,0 pontos & 12 alunos & 15 alunos & 2 alunos \\
\hline $\begin{array}{l}4 \text { - Julgar informações como verdadeiras } \\
\text { ou falsas - } 12,5 \text { pontos }\end{array}$ & 13 alunos & 18 alunos & 1 aluno \\
\hline 5 - Relacionar passado x presente - 11,5 pontos & 20 alunos & 10 alunos & \\
\hline 6 - Identificar alternativas corretas - 15,0 pontos & 17 alunos & 8 alunos & 1 aluno \\
\hline 7 - Levantar hipóteses coerentes - 16,0 pontos & 19 alunos & 11 alunos & \\
\hline 8 - Explicar um processo histórico - 10,0 pontos & 15 alunos & 12 alunos & \\
\hline
\end{tabular}

Fonte: elaborado pela autora

Como podemos observar, os resultados apontam para habilidades que precisam ser retrabalhadas com os alunos, tais como organizar e julgar a veracidade de informações, concernentes ao tema da Pré-História.

Por outro, demonstraram que adquiriram as ferramentas fundamentais do historiador, que os empoderam de forma autônoma para a investigação histórica.

Analisando os dados do Gráfico 1, notamos que o aproveitamento apresentado pelas duas turmas foi, de modo geral, satisfatório, e a maioria dos alunos conseguiu vencer o desafio proposto para eles na Figura 1, ultrapassando a média dos 70 pontos.

Gráfico 1 - Aproveitamento/Notas obtidas

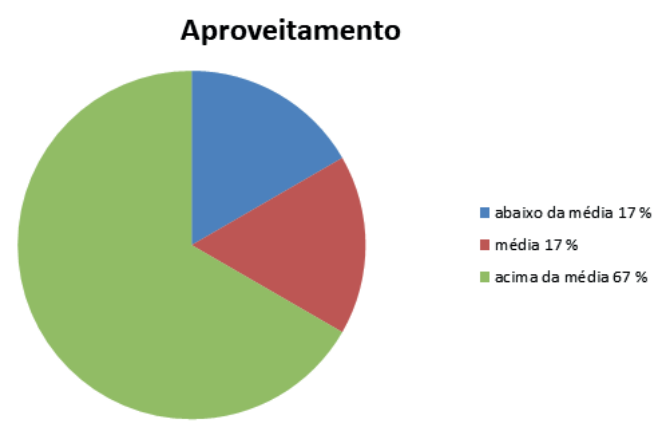

Fonte: elaborado pela autora.

\section{Sob O Olhar dos Alunos}

Nesta última etapa, pretendemos analisar o que representou esta proposta pedagógica para os alunos. Para tanto, elaboramos um questionário com sete perguntas objetivas, no formato Google Forms, no qual, de maneira anônima, os alunos puderam expressar o que essa experiência significou para cada um deles?.

Os alunos responderam ao questionário na própria Escola, em uma de nossas aulas. Esse feedback nos serviu de parâmetro para avaliarmos se nossa estratégia pedagógica de pensar, planejar e aplicar uma prova game de fato teria cumprido seu papel facilitador e motivador, ou não.

Conforme os resultados apontados pelos Gráficos a seguir, percebemos que a prova, nesse formato, foi uma novidade positiva para a maioria dos alunos, pois afirmaram ter maior facilidade para demonstrarem seu aprendizado, superando a ansiedade e o medo comuns que antecedem as avaliações finais.

1 Durante a resposta dos alunos, tivemos uma queda no sinal da Internet, o que deixou em dúvida um dos alunos quanto ao envio de suas respostas. Posteriormente, constatamos que, por essa razão, há uma resposta a mais do que o número de alunos. Porém, esse fato não representou impacto significativo na análise dos resultados obtidos. 
Observamos, também, que os alunos, em sua totalidade, sentiram-se motivados a fazer a prova depois de descobrirem que não fariam uma prova tradicional e, sim, uma prova game, resultando na satisfação de $90 \%$ dos alunos com a nota obtida.

Além disso, metade dos alunos afirmou não ter tido dificuldades com a prova game; porém $35 \%$ sinalizaram dificuldade com as pergun-tas dissertativas.

Nosso desafio foi planejar a avaliação somativa no formato de um jogo, sob a incerteza de colocar em xeque o trabalho pedagógico desenvolvido ao longo de todo um trimestre, a depender da receptividade da proposta frente ao desempenho dos alunos.

Não obstante, a motivação demonstrada pelos alunos em fazer novas provas como essa legitimou nossa proposta e provou que sim, o jogo utilizado com objetivo pedagógico cumpriu seu papel.

Gráfico 2 - Experiências anteriores

Você já havia feito uma prova no formato de um jogo? 31 respostas

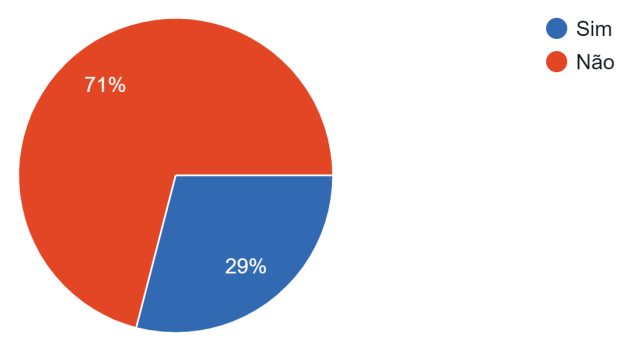

Fonte: elaborado pela autora.

Gráfico 3 - Validade da proposta

Você achou mais fácil ou mais difícil fazer a prova como um jogo? 31 respostas
Gráfico 4 - Aspectos socioemocionais: o antes Antes da prova você se sentiu: 31 respostas

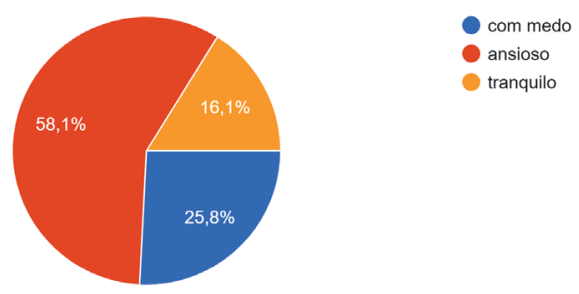

Fonte: elaborado pela autora

Gráfico 5 - Aspectos socioemocionais: o depois Quando você descobriu que a prova era como um jogo você se sentiu: 31 respostas

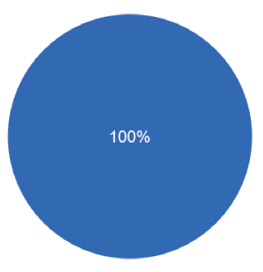

animado para fazer a prova desanimado para fazer a prova

Fonte: elaborado pela autora

Gráfico 6 - Autoavaliação

Você ficou feliz com a nota que tirou na prova? 31 respostas

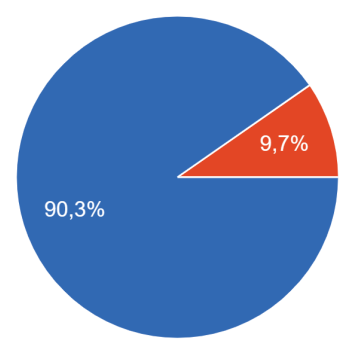

Fonte: elaborado pela autora

\section{Gráfico 7 - Identificando dificuldades}

Qual foi sua maior dificuldade nesse formato de prova? 31 respostas

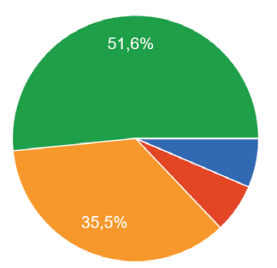

- Com a leitura

Com as perguntas objetivas (de marcar " $\mathrm{X")}$

Com as perguntas dissertativas

escrever a resposta)

- Não tive dificuldades 


\section{Gráfico 8 - Perspectivas futuras}

Você gostaria de fazer as próximas provas nesse formato de jogo? 31 respostas

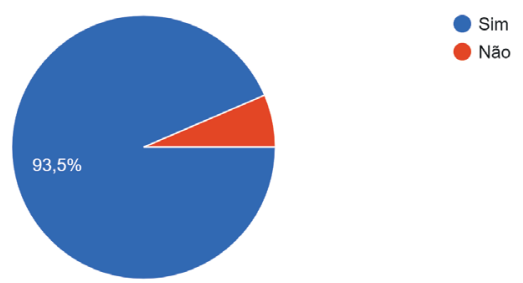

Fonte: elaborado pela autora.

\section{Considerações Finais}

O pensar e repensar métodos e estratégias pedagógicas é fundamental para o aperfeiçoamento da prática docente compromissada com a Educação.

Nesse sentido, a sistematização da experiência didática aqui por nós compartilhada visa a contribuir para inspirar outros educadores em sua prática em sala de aula.

Procuramos demonstrar, ao longo do relato de nossa prática, como o jogo foi utilizado como instrumento facilitador para entrar no campo do abstrato com crianças de 11 anos de idade, considerando todas as incertezas e inseguranças que envolvem a transição do Ensino Fundamental I para o Ensino Fundamental II.

Nossa intenção foi utilizar o jogo não de forma ilustrativa e simplificadora, mas sim, numa perspectiva de estratégia didática de encorajamento de participação ativa dos alunos, instigando sua criatividade e a motivação de progredir em suas conquistas, materializadas em cada enigma desvendado, o que, sem dúvida, irá se refletir numa postura mais engajada frente aos desafios do jogo da vida, que cada um deles enfrentará na trajetória individual.

\section{Referências}

BROUGÈRE, G. Jogo e Educação. Porto Alegre: Artes Médicas, 2002.

COSTA, M. A. F. Ensino de História e Games: Dimensões Práticas em Sala de Aula. Curitiba: Appris, 2017.

FREIRE, P. Pedagogia da autonomia: saberes necessários à prática educativa. São Paulo: Paz e. Terra, 1996.

KISHIMOTO, T. M. (org.) Jogo, Brinquedo, Brincadeira e a Educação. 14.ed. São Paulo: Cortez, 2000.

LEFFA, V. et al. Quando jogar é aprender: o videogame na sala de aula. Rev. Estudos Linguísticos, Belo Horizonte, v. 20, n. 1, p. 209-230, 2012.

LEFFA, V. J.; PINTO, C. M. Aprendizagem como vício: $O$ uso de games em sala de aula. Revista (Con)Textos Linguísticos, Vitória, v. 8, n. 10.1, p. 358-378, 2014.

MATTAR, J. Games em educação: como os nativos digitais aprendem. São Paulo: Person Prentice Hall, 2010.

MCGONIGAL, J. Gaming can make a better world. 2010. Disponivel em: http://www.ted.com/ talks/jane_mcgonigal_gaming_can_make_a_ better_world.html. Acesso em: 21 jun. 2019. 